EPiC Series in Built Environment
Volume 1, 2020, Pages 329-337
$\begin{gathered}\text { Associated Schools of Construction Proceed- } \\ \text { ings of the 56th Annual International Conference }\end{gathered}$

\title{
How Construction and Capital Resource Availability Drive Regional Post-disaster Housing Reconstruction
}

\author{
Srijesh Pradhan and Erin Arneson, Ph.D. \\ Colorado State University \\ Fort Collins, CO
}

Natural hazards cause damages to the U.S. residential housing stock every year, and reconstruction of damaged housing is essential for the long-term community resilience. Post-disaster housing reconstruction in the U.S. is a market-driven process, influenced by the availability of construction and capital resources. Previous case studies have illustrated that housing reconstruction outcomes are uneven across different disaster-affected regions of the U.S. and may be attributable to varying availability of regional construction and capital resources. However, there is a lack of quantitative studies exploring the relationships between resourcing factors and housing reconstruction outcomes across varying geographical regions of the U.S. Using Ordinary Least Squares (OLS) regression and Geographically Weighted Regression (GWR), this study aims to: (1) quantify the relationships between pre-disaster construction and capital resource availability and post-disaster housing reconstruction outcomes at a regional scale; and (2) explore spatially varying relationships between resourcing factors and reconstruction outcomes. The Northeast census region of the U.S. is used as a case study for this research, due to unprecedented levels of residential housing disaster damages from 2011-2012. Results from the case study highlighted significant relationships between resource availability and reconstruction outcomes, and the relationships varied across the study region.

Key Words: Residential Housing Reconstruction, Disasters, GIS

\section{Introduction}

The U.S. residential housing stock is vulnerable to the rising frequency of natural hazards. Over the last decade, total residential losses due to disasters have reached over $\$ 10$ billion dollars (FEMA, 2014). Swift reconstruction of damaged residential housing is essential for the long-term recovery of households and communities. Post-disaster residential reconstruction uses a market-driven resourcing approach in the U.S. The market-driven model depends on the availability of private sector resources to facilitate and finance housing reconstruction. However, the permanent housing reconstruction process is often prolonged, and outcomes are not uniform across disaster-affected regions of the U.S. The slow and differential recovery across regions can be attributed to differences in regional 
availability of resources. At the regional scale, construction industry (e.g., labor and materials) and homeowner capital resources (e.g., financing) constitute two core resourcing forces that influence post-disaster residential housing reconstruction (Arneson et al., 2020). On the one hand, availability of construction resources is determined by the capacity of a regional construction industry to supply labor and material to meet demand. However, regional construction capacity is not uniform across geographical regions of the U.S. (Arneson et al., 2020). Moreover, following large-scale disasters, regional construction capacity is constrained due to excessive new demand for reconstruction. Labor shortages following disasters not only delay housing reconstruction but also result in a demand-surge of labor prices (Olsen \& Porter, 2013). On the other hand, the availability of capital resources is influenced by the socioeconomic status of households and determines if homeowners have the financial capacity to purchase construction resources necessary for housing reconstruction. However, regional pre-disaster inequities in household socioeconomic status lead to differential capital resource availability and uneven residential housing reconstruction outcomes (Peacock et al., 2014).

Ultimately, few studies have explored the geographically varying relationships among construction and capital resourcing forces and residential housing reconstruction outcomes. To address the research gaps, this study aims to address the following research questions: (i) How do pre-disaster

construction and capital resource availability influence regional post-disaster housing reconstruction outcomes? and (ii) How does the relationship between pre-disaster resource availability and post-disaster housing reconstruction outcomes vary across regions?

\section{Literature Review}

Despite the importance of resource availability for post-disaster residential housing reconstruction, there are few studies examining the influence of construction and capital resource availability on reconstruction outcomes, or research exploring how such resourcing forces vary geographically. Within the limited existing literature, researchers view core resourcing forces as composed of multiple resourcing factors. These resourcing factors are metrics which can be tracked and measured to assess broader construction (e.g., number of laborers) and capital (e.g., household socioeconomic status such as income) resource availability. Previous quantitative studies have modeled changes in housing conditions (e.g. home values) caused by disasters using resourcing factors. Zhang \& Peacock (2009) found significant correlations between pre-disaster socioeconomic conditions of single-family households and their recovery trajectories following Hurricane Andrew, which hit Florida in 1992. Arneson et al. (2020) developed a quantitative model to predict post-disaster reconstruction outcomes in the U.S. by regressing building permits with pre-disaster construction capacity and found that predisaster construction labor availability significantly influenced post-disaster reconstruction outcomes.

Qualitative case studies have also discussed resourcing factors that impede homeowners from acquiring construction and capital resources, along with the repercussions of those resourcing bottlenecks in reconstruction outcomes. Chang-Richards et al. (2013) studied the 2009 Victorian Bushfires in Australia and highlighted that local construction market conditions and socioeconomic status of households influenced the availability of construction and capital resources. Furthermore, case studies have suggested that pre-disaster socioeconomic conditions of households and construction capacity shape the reconstruction environment of a region (Chang et al., 2012). However, geographically varying construction capacity (Arneson et al., 2020) and inequities in socioeconomic conditions of households (Peacock et al., 2014) can produce unique reconstruction outcomes across regions. Since the region-specific resourcing context drives regional reconstruction outcomes, the role of geography cannot be ignored while studying reconstruction outcomes through a resourcing lens. 


\section{Research Methods}

This study develops predictive models using Geographic Information System (GIS) software to explore how construction and socioeconomic resourcing factors drive regional patterns of residential housing reconstruction in the U.S. A multi-step process was adopted to: (1) determine the case study disaster region and time frame; (2) collect county-level data for construction and socioeconomic resourcing factors; and (3) analyze data in GIS software using Ordinary Least Squares (OLS) and Geographically Weighted Regression (GWR) statistical models.

\section{Study region, Time frame and Disaster context}

The case study region included eight states of the Northeast census region-Connecticut, Massachusetts, New Hampshire, New Jersey, New York, Pennsylvania, Rhode Island, and Vermont. This region was hit by multiple federally-declared disasters from 2011-2012, and were some of the costliest disaster years in recent U.S. history. Multiple large-scale disasters such as Hurricane Irene (2011), Tropical Storm Lee (2011), and Hurricane Sandy (2012) caused substantial residential losses in the Northeast region, with total damages exceeding \$1.5 billion dollars in 2011 and \$2.5 billion dollars in 2012. The year 2010 was chosen as a baseline period to measure the pre-disaster construction and capital resource availability.

\section{Data Collection}

County-level data on residential damages, construction resourcing factors, socioeconomic resourcing factors, and reconstruction outcomes came from three publicly available data sources: Federal Emergency Management Agency (FEMA), U.S. Bureau of Labor Statistics (BLS), and U.S. Census Bureau's American Community Survey (ACS). Data was collected for 195 counties of the Northeast census region. Residential damages were identified from the publicly available Archived Housing Assistance Program Data from the FEMA website (FEMA, 2014). FEMA keeps track of all disasterrelated residential losses in the U.S. following federally declared disasters.

First, data for construction resourcing factors were collected for the 2010 pre-disaster year from the Quarterly Census of Labor and Wages published by the BLS (U.S. Bureau of Labor Statistics, 2019). Availability of regional construction labor resources was indicated by the location quotient (LQ) of the annual average establishments and employment of the North American Industry Classification System (NAICS) based industry sector, provided by the BLS. Industry LQ quantify how concentrated an industry (e.g., number of construction establishments or employees) is within a region compared to the national level (Bureau of Economic Analysis, 2018). The LQ of annual average employment of NAICS Sector 23 industry, denoted by LQ_EMP, and LQ of annual average establishments of NAICS Sector 238 industry, denoted by LQ_EST, were used to indicate construction labor resourcing factors. NAICS Sector 23 is comprised of establishments primarily engaged in the construction works of residential buildings, commercial buildings, utilities, and infrastructures while NAICS Sector 238 represented Specialty Trade Contractors subsector, comprised of establishments involved in construction of buildings. Availability of regional construction material resources was measured based on the LQ of annual average establishment count of NAICS Sector 423 industry, denoted by LQ_MATERIAL. NAICS Sector 423 represented merchant wholesalers engaged in the wholesale of durable goods, including merchant wholesalers selling construction materials such as lumber and wood (NAICS 42331), masonry (NAICS 42332), and roofing and siding (NAICS 42333). 
Second, county-level data for the socioeconomic conditions of owner-occupied households were collected from the U.S. Census Bureau's ACS 5-year estimates for the pre-disaster year 2010 (U.S. Census Bureau, 2019). Availability of regional capital resources was measured for owner-occupied households based on socioeconomic indicators (e.g., income, education status, and mortgage status). INCOME was defined as the median household income of owner-occupied households in U.S. dollars. EDUCATION was defined as the percentage of owner-occupied households with the education status of bachelor's degree or above. MORTGAGE was defined as the percentage of owner-occupied households with a home mortgage. These variables were selected since they act as a catalyst, either favoring or constraining homeowners' ability to acquire capital resources. For instance, the authors hypothesized that factors such as income and education status were positive catalysts while mortgage status was a negative catalyst for homeowners to access capital.

Lastly, post-disaster residential reconstruction outcomes were measured based on the percent change in median home values $(M H V)$ from pre-disaster year to post-disaster year. Data for median home values were collected from the Census Bureau's ACS 5-year estimates from the years 2010-2014. For counties that were hit by disasters in 2011, the change in median home values was measured from pre-disaster year 2010 to post-disaster year 2013 since previous case studies have shown that housing reconstruction is usually completed within the timeframe of two years (Rathfon et al., 2013). For counties hit by disasters both in 2011 and 2012, the change in median home values was measured from 2010 to 2014 to consider one additional year for reconstruction. Changes in home values capture long-term reconstruction trajectory, and it was expected that the households with access to construction and capital resources were able to improve their home values deteriorated by disasterrelated damages. Table 1 provides descriptive statistics for the resourcing factors discussed above.

\section{Data Analysis}

A multi-step data analysis process was carried out to: (1) import and organize data in GIS software, and (2) develop a Global OLS model, and (3) develop a local GWR model. ArcGIS Pro 2.4 software (ESRI, 2019) was used to analyze the data as it had spatial regression tools to develop the GWR model. County-level data was imported to ArcGIS Pro software and linked to shapefiles of each county using geographic identifiers (GEOID). Shapefiles are an open file format that stores the location, geometric shape, and attribute information of geographic features such as counties. GEOIDs are numeric codes that uniquely identify all statistical geographic areas for which the Census Bureau tabulates data. The local coefficients produced by GWR were mapped using ArcGIS Pro.

\section{Global OLS Model}

OLS regression is a generalized linear modeling technique to predict the values of a continuous outcome variable using one or more predictor variables. The first step in the modeling process was the development of a global OLS model. The global OLS model for examining the influence of resourcing factors on reconstruction outcomes was specified as:

$\% \Delta$ Reconstruction $_{i}=\beta_{o}+\Sigma_{k} \beta_{k}$ Construction $_{i k}+\Sigma_{l} \beta_{l}$ Capital $_{i l}+\varepsilon_{i}$

where: \% $\Delta$ Reconstruction $_{i}$ indicates reconstruction outcomes estimated for county $i$, measured as percent change in median home value from pre-disaster year to post-disaster year; Construction represents construction market resourcing factors measured at county $i$, which includes variables such as construction establishments, construction employment, and wholesale establishments; Capital $_{i}$ 
represents capital resourcing factors measured at county $i$, which includes variables such as income, education, and mortgage status; $\beta_{o}$ is the intercept; $\beta_{k}$ is the regression coefficient associated with construction resourcing variables; $\beta_{l}$ is the regression coefficient associated with capital resourcing variables; and $\varepsilon_{i}$ is residuals of the OLS regression.

The regression coefficients $\left(\beta_{k}\right.$ and $\beta_{l}$ ) are termed as global coefficients as they remain constant for the entire region. The coefficients describe a positive or negative effect on the growth rate of median home values, from the pre-disaster period to the post-disaster period. The residuals of the OLS were mapped and tested for spatial autocorrelation using Moran's I statistic. The existence of spatial autocorrelation indicates that the model may include spatially varying relationships.

\section{Geographically Weighted Regression}

One of the limitations of OLS is its assumption that the measurement of the relationship between predictor and outcome variable is uniform for the entire region being studied. However, spatial data (e.g. data located in geographical regions such as counties) may not follow this assumption. As regionspecific resource availability influences the reconstruction outcomes of a region, the resourcing context of each region can cause the relationships between resource availability and reconstruction outcomes to vary across regions. Since OLS might hide potentially critical local variations in the relationships, GWR was used in addition to OLS in this study as it allowed to explore local variations in the relationships (Fotheringham et al., 2002). The GWR technique extends the OLS regression of Eq. (1) by adding a geographic location parameter and allowing the regression coefficients to vary across regions. The same variables used in the OLS model was used in the GWR model. The GWR model was specified as:

$\% \Delta$ Reconstruction $_{i}=\beta_{o}\left(u_{i}, v_{i}\right)+\Sigma_{k} \beta_{k}\left(u_{i}, v_{i}\right)$ Construction $_{i k}+\Sigma_{l} \beta_{l}\left(u_{i} v_{i}\right)$ Capital $_{i l}+\varepsilon_{i}$

The coefficients $\beta_{k}$ and $\beta_{l}$ in Eq. (2) are a function of the coordinates of the centroid of the county $i$, denoted by $\left(u_{i}, v_{i}\right)$. GWR estimates these coefficients using a weighing function centered on target county $i$ such that locations nearer to $i$ will have more influence on the estimation of regression coefficients at $i$ compared to locations farther away from $i$. Target county was defined as the county whose local regression coefficients were estimated through weighted observations in neighboring counties. In GWR, it was important to select two parameters: (1) bandwidth selection, and (2) weighing scheme selection. First, bandwidth determines the number of neighboring counties to be included in the observation to estimate the local coefficients. Bandwidth can be fixed or adaptive. Fixed bandwidth specifies a fixed distance to each target county, while adaptive bandwidth assigns a specified number of neighboring counties to each target county to estimate the regression coefficients. In adaptive bandwidth, the observation area adapts to become smaller where counties are dense and larger where counties are sparse. Adaptive bandwidth was chosen for this study as it accounts for the variation in the size of counties. The optimum number of neighboring counties was selected based on the process that minimized the Akaike Information Criteria (AICc) since it maximized model significance (Fotheringham et al., 2002). Second, the weighting scheme determines how quickly weights decrease as distance increases. Weighing scheme can be either Gaussian or Bisquare. In Gaussian scheme, all counties receive weights which decreases exponentially as distance from target county increases. Bisquare weighing scheme works similarly as Gaussian with an exception that the counties falling outside of the specified bandwidth are assigned zero weights. Bisquare weighing scheme was used in this study so that only the resourcing variables of counties in close proximation to target county contributed to the estimation of regression coefficients. 


\section{Results}

\section{Global OLS Model}

OLS model was developed at a county-level to establish global relationships between resourcing variables and reconstruction outcomes. The descriptive statistics of the variables and the results of the OLS model are presented in Table 1 and Table 2 respectively. With an adjusted R-squared value of 0.58 , the OLS model explained about $58 \%$ of the variation in percent changes in median home values through construction and capital resourcing variables. All the predictor variables were statistically significant at the 0.05 level. A significant linear relationship between the resourcing factors and reconstruction outcomes was found, as highlighted by a significant joint F-statistic and joint Wald statistic. The Jarque-Bera statistic was not significant, which indicated that the model was unbiased, and all the key variables were present in the model. The Koenker (BP) statistic had a significant pvalue indicating a presence of spatial nonstationarity in the model. In other words, the relationships between resourcing factors and reconstruction outcomes varied across study region counties. Spatial autocorrelation was found in the residuals of the OLS model (Moran's I = 0.27; z = 7.61; $\mathrm{p}<0.001$ ).

Table 1

Descriptive Statistics for variables used in the study

\begin{tabular}{lrrrr}
\hline \multicolumn{1}{c}{ Variable } & \multicolumn{1}{c}{ Minimum } & \multicolumn{1}{c}{ Maximum } & \multicolumn{1}{c}{ Mean } & \multicolumn{1}{c}{ Std. Deviation } \\
\hline MHV & -16.35 & 17.89 & 0.80 & 7.63 \\
INCOME & $36,163.00$ & $134,116.00$ & $66,480.78$ & $17,539.96$ \\
EDUCATION & 11.09 & 82.03 & 31.16 & 11.89 \\
MORTGAGE & 39.11 & 78.10 & 63.30 & 7.80 \\
LQ_MATERIAL & 0.07 & 1.52 & 0.78 & 0.27 \\
LQ_EMP & 0.30 & 3.33 & 0.93 & 0.36 \\
LQ_EST & 0.17 & 2.65 & 1.13 & 0.33 \\
\hline
\end{tabular}

Table 2

Summary of the Global OLS model

\begin{tabular}{lrrlr}
\hline \multicolumn{1}{c}{ Variable } & Coefficient & t-Statistic & \multicolumn{1}{c}{-value } & \multicolumn{1}{c}{ VIF } \\
\hline Intercept & 32.602623 & 9.185534 & $0.000000^{*}$ & - \\
INCOME & -0.000338 & -6.622205 & $0.000000^{*}$ & 6.400528 \\
EDUCATION & 0.188404 & 2.776871 & $0.004277^{*}$ & 5.166328 \\
MORTGAGE & -0.282665 & -3.255922 & $0.009223^{*}$ & 3.658551 \\
LQ_MATERIAL & 5.739948 & 3.927212 & $0.000067^{*}$ & 1.233631 \\
LQ_EMP & 2.716352 & 2.089390 & $0.048475^{*}$ & 1.671244 \\
LQ_EST & -3.842435 & -2.358372 & $0.021475^{*}$ & 2.155797 \\
Adjusted R-Squared & 0.58 & \multicolumn{2}{c}{ AICc } & 1177.722168 \\
Joint F-Statistic & 46.556695 & p-Value & $0.000000^{*}$ \\
Joint Wald Statistic & 407.580251 & \multicolumn{2}{c}{ p-Value } & $0.000000^{*}$ \\
Koenker (BP) Statistic & 13.845754 & p-Value & $0.031407^{*}$ \\
Jarque-Bera Statistic & 0.416062 & p-Value & 0.812182 \\
* indicates a statistically significant p-value $(\mathrm{p}<0.05)$ & \\
\hline
\end{tabular}




\section{GWR Model}

The GWR model produced different coefficients for each county. The range of local GWR coefficients is shown in Table 3. The change in both magnitude and direction of the coefficients suggests that the relationships between resourcing factors and reconstruction outcomes varied across study region counties. The GWR model showed significant improvements over the OLS model. First, the Adj $\mathrm{R}^{2}$ increased from 0.58 in the OLS model to 0.79 in the GWR model. The adjusted $\mathrm{R}^{2}$ for the local GWR model ranged from 0.23 to 0.89 . The GWR model explained up to $89 \%$ of the variation in percent changes in median home values. Second, the GWR model had a smaller AICc (1087.82) than the OLS model (1177.72). Lastly, residuals for the GWR were tested for spatial autocorrelation. No spatial autocorrelation was found (Moran's $\mathrm{I}=0.041 ; \mathrm{z}=1.23 ; \mathrm{p}=0.21$ ) which indicated that the GWR model was properly conducted. Figure 1 indicates the spatial distribution of local GWR coefficients for LQ of construction employment and wholesale establishments.

Table 3

Summary of GWR model

\begin{tabular}{lrr}
\hline \multicolumn{1}{c}{ Variable } & Coefficient $\beta$-min & Coefficient $\beta$-max \\
\hline Intercept & -5.47 & 61.26 \\
INCOME & -0.000142 & 0.000542 \\
EDUCATION & -0.53 & 0.55 \\
MORTGAGE & -0.90 & 0.55 \\
LQ_MATERIAL & -4.90 & 12.59 \\
LQ_EMP & -2.00 & 11.61 \\
LQ_EST & -11.06 & 3.95 \\
Adjusted R-squared & 0.7952 & \\
AICc & 1087.8213 & \\
\hline
\end{tabular}

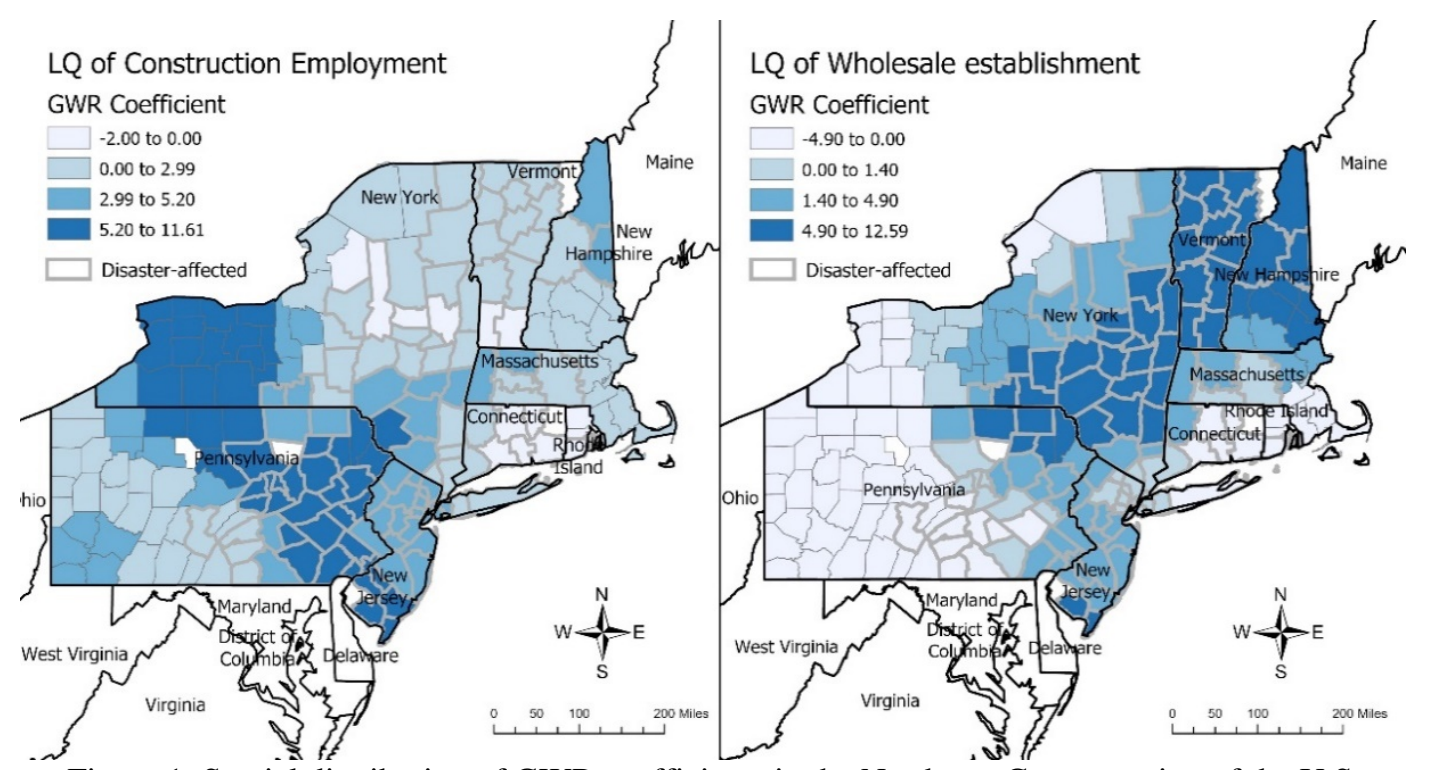

Figure 1: Spatial distribution of GWR coefficients in the Northeast Census region of the U.S. 


\section{Discussion and Conclusion}

This study has quantified the global and local relationships between pre-disaster resource availability (measured using construction and capital resourcing factors) and post-disaster reconstruction outcomes at a regional level. Pre-disaster construction and capital resource availability were found to be statistically significant predictors of post-disaster reconstruction outcomes. GWR statistical analysis has successfully identified regional variations in relationships between pre-disaster resource availability and post-disaster reconstruction outcomes across the study region counties.

Post-disaster housing reconstruction outcomes in the Northeast Census region of the U.S., following the 2011 and 2012 disaster events, have been found to be significantly and positively correlated with greater regional labor employment and material wholesale establishments. These findings are consistent with literature highlighting the dependence of post-disaster housing reconstruction on the availability of market resources in countries with mature construction sectors, such as the U.S. (Chang-Richards et al., 2013). However, this study digs deeper by focusing on how construction market forces locally influence reconstruction outcomes across disaster-affected regions. For instance, the GWR map (Fig. 1) reveals that some disaster-affected counties have relatively strong positive correlations between reconstruction outcomes and both the LQ of construction employment ( $\beta$ ranging from 5.20 to 11.61) and the LQ of material wholesale establishments ( $\beta$ ranging from 4.90 to 12.59). Changes in pre-disaster labor and material availability in regions with strong positive or negative correlations experienced more pronounced repercussions on reconstruction outcomes.

GIS statistical analysis methods, such as OLS and GWR, can help facilitate decision-making for stakeholders involved with pre-disaster risk mitigation or post-disaster recovery and reconstruction. These stakeholders can use such resource availability maps to identify counties that are more vulnerable to reconstruction delays resulting from inadequate availability of construction and capital resourcing factors. The GWR model shows how resources located within neighboring regions are crucial in shaping reconstruction outcomes in adjacent disaster-affected regions. GWR maps can help community stakeholders with local decision-making power, such as emergency managers or city managers, to assess their local community's vulnerability to disasters and begin coordinating with contractors and other disaster stakeholders in adjacent counties to improve resource sharing strategies.

Capital resource availability is a crucial factor in determining households' decision to rebuild or relocate. There has been a consensus in the literature on the major socioeconomic variables influencing capital resource availability for reconstruction such as income, education, and mortgage status (Peacock et al., 2014). However, the findings of this study reveal that the influence of socioeconomic factors on reconstruction outcomes vary geographically based on local conditions. This can aid homeowners in decision-making process of rebuilding or relocating. For example, regions with more unpaid mortgages have negative correlations with reconstruction outcomes, as it adds an additional financial burden on homeowners trying to access capital resources for reconstruction. While the global model shows negative correlation between income and reconstruction outcomes, the GWR model showed positive correlations in some counties. Also, regions with a greater number of educated households experienced more positive reconstruction outcomes. When creating pre-disaster mitigation strategies and resource planning, stakeholders and policy makers should consider socioeconomic conditions of community households as well as local construction resource availability. The availability of GWR-based resourcing maps (e.g., Fig 1) could quickly highlight a community's disaster vulnerability, especially in locations where global resourcing factors exhibit statistically significant regional variation. With the aid of such resourcing maps depicting regional variation of these relationships, residential communities can identify and take proactive steps to overcome resourcing bottlenecks prevalent within geographical boundaries. 
The measure of the influence of construction and capital resource availability on reconstruction outcomes through global statistics (e.g., OLS) may help decision-makers in assessing the critical resourcing bottlenecks for housing reconstruction. However, inferences solely based on global results may not be suitable in specific local settings as revealed by this case study. This study addresses a critical gap in housing reconstruction literature by determining how region-specific resourcing context locally drive reconstruction outcomes across disaster-affected regions. Local parameter maps can be a powerful tool for decision-makers to identify regions vulnerable to resourcing crisis for post-disaster housing reconstruction and can assist them in developing robust post-disaster resource planning and policy mechanisms. Future research will identify other resourcing bottlenecks that hinder permanent housing reconstruction and map local parameters across all disaster-affected regions of the U.S.

\section{References}

Arneson, E., Javernick-Will, A., Hallowell, M., \& Corotis, R. (2020). Predicting Postdisaster Residential Housing Reconstruction Based on Market Resources. Natural Hazards Review, 21(1), 04019010. https://doi.org/10.1061/(ASCE)NH.1527-6996.0000339

Bureau of Economic Analysis. (2018). What are location quotients (LQs)? Retrieved October 9, 2019, from Bureau of Economic Analysis website: https://www.bea.gov/help/faq/478

Chang, Y., Wilkinson, S., Potangaroa, R., \& Seville, E. (2012). Managing resources in disaster recovery projects. Engineering, Construction and Architectural Management, 19(5), 557580. https://doi.org/10.1108/09699981211259621

Chang-Richards, Y., Wilkinson, S., Potangaroa, R., \& Seville, E. (2013). Resource challenges for housing reconstruction: A longitudinal study of the Australian bushfires. Disaster Prevention and Management: An International Journal, 22. https://doi.org/10.1108/09653561311325316

ESRI. (2019). ArcGIS Pro (Version 2.4.2). Retrieved from https://www.esri.com/enus/arcgis/products/arcgis-pro/overview

FEMA. (2014). Archived Housing Assistance Program Data. Retrieved September 30, 2019, from Federal Emergency Management Agency website: https://www.fema.gov/medialibrary/assets/documents/30714

Fotheringham, A. Stewart., Brunsdon, C., \& Charlton, M. (2002). Geographically weighted regression: The analysis of spatially varying relationships. Chichester: Wiley.

Olsen, A. H., \& Porter, K. A. (2013). Storm Surge to Demand Surge: Exploratory Study of Hurricanes, Labor Wages, and Material Prices. Natural Hazards Review, 14(4), 247-257. https://doi.org/10.1061/(ASCE)NH.1527-6996.0000111

Peacock, W. G., Zandt, S. V., Zhang, Y., \& Highfield, W. E. (2014). Inequities in Long-Term Housing Recovery After Disasters. Journal of the American Planning Association, 80(4), 356-371. https://doi.org/10.1080/01944363.2014.980440

Rathfon, D., Davidson, R., Bevington, J., Vicini, A., \& Hill, A. (2013). Quantitative assessment of post-disaster housing recovery: A case study of Punta Gorda, Florida, after Hurricane Charley. Disasters, 37(2), 333-355. https://doi.org/10.1111/j.1467-7717.2012.01305.x

U.S. Bureau of Labor Statistics. (2019). Quarterly Census of Employment and Wages. Retrieved August 1, 2019, from https://www.bls.gov/cew/downloadable-data-files.htm

U.S. Census Bureau. (2019). American Community Survey (ACS). Retrieved October 9, 2019, from United States Census Bureau website: https://www.census.gov/programssurveys/acs/about.html

Zhang, Y., \& Peacock, W. G. (2009). Planning for Housing Recovery? Lessons Learned From Hurricane Andrew. Journal of the American Planning Association, 76(1), 5-24. https://doi.org/10.1080/01944360903294556 